\title{
An Incentive for Risk Taking: The Case of Banks in ASEAN 6
}

\author{
Thanh Phu Ngo ${ }^{1,2}$ \\ ${ }^{1}$ Faculty of Finance and Banking, University of Economics and Law, Ho Chi Minh City, Vietnam \\ ${ }^{2}$ Vietnam National University, Ho Chi Minh City, Vietnam \\ Correspondence: Thanh Phu Ngo, Faculty of Finance and Banking, University of Economics and Law, Vietnam \\ National University, Ho Chi Minh City, Vietnam. E-mail: thanhnp@uel.edu.vn
}

Received: April 18, 2020

Accepted: July 21, 2020

Online Published: September 3, 2020

doi:10.5430/rwe.v11n5p129

URL: https://doi.org/10.5430/rwe.v11n5p129

\begin{abstract}
Incorporating credit risk into technical efficiency to investigate possible effects of the risk on efficiency for a sample of 276 unique ASEAN commercial banks over the period $2000-2015$, we find a striking U-shaped effect of credit risk on both risk-free efficiency and risk-adjusted efficiency. The U-shaped relationship exists in both large banks and small banks. This finding is new and raises a concern for bank regulators in monitoring and controlling bank risks since banks have an incentive to become more efficient by following greater risk-taking strategies.
\end{abstract}

Keywords: bank efficiency, risk, radial and nonradial measures

\section{Introduction}

Efficiency has been considered as an important benchmark to measure performance in the banking sector. Conventionally, bank efficiency measurement has focused on measuring purely good outputs (e.g. loans and other earning assets) relative to inputs (e.g. deposits, personnel). It means that in order to improve the efficiency level, a bank needs to either maximize its outputs (an output-oriented measurement) or minimize its inputs (an input-oriented measurement). The conventional approach to measuring bank efficiency neglected the existence of bad outputs has been questioned about the biases of the result. These arguments have been supported by the recent empirical studies in bank efficiency measurement field (e.g. Epure and Lafuente, 2015; Fukuyama and Weber, 2008; Huang et al, 2015; Huang and Chung, 2016; Kenjegalieva et al., 2009; Park and Weber, 2006).

Understanding how risk affects efficiency is important for bank regulators. To pursue better efficiency banks may engage on more risk-taking, which can result in a cost capital lost or loan loss provision. If a positive relationship between risk and efficiency exits, bank managers have incentives to have excessive risk-taking strategies in order to achieve greater efficiency. In the global perspective, too much risk-taking leads to reduced lending and micro and macro-financial fragility during the global financial crisis of 2007-2008 (Shleifer and Vishny, 2010). Then banking regulators propose higher capital and liquidity standards (Basel Committee on Banking Supervision, 2010, 2014). These standards aim to discourage risk-taking from financial institutions.

Risk and efficiency are two sides of banking operation. However, literature mostly focuses on a linear effect on efficiency (Berger and De Young, 1997; Fiordelisi, Marques-Ibanez, and Molyneux, 2011; Mamatzakis, 2015; Silva et al., 2016). Moreover, risk is ignored in the literature examining efficiency analysis in the ASEAN banking sector (e.g. Chan, Koh, and Kim, 2016; Gardener, Molyneux, and Nguyen-Linh, 2011; Wong and Deng, 2016; Zaini Abd Karim, Chan, and Hassan, 2010). This paper aims at investigating whether a nonlinear effect of risk on efficiency exists and incorporating risk in measuring bank efficiency.

To examine a possible nonlinear effect of risk on efficiency and incorporate risk in measuring bank efficiency, this paper follows a two-stage analysis. In the first stage, we compute radial and nonradial risk-free and risk-adjusted technical efficiency (TE) measures in the first stage. The risk-free TE is an efficiency score with only good outputs, and the risk-adjusted TE is an efficiency score with both good and bad outputs. We employ credit risk as a bad output. To compute the risk-adjusted TE (efficiency with credit risk), we construct a ratio which is equal to one minus the percentage of net loans in gross loans. The usage of the ratio helps us to either maximize good outputs and minimizing bad output simultaneously. In the second stage, we examine the effect of the credit risk on both risk-free and risk-adjusted TE by using truncated regressions and Ordinary least square (OLS). We use the ratio of nonperforming loan ratio to proxy for credit risk. 
We focus on ASEAN area because the creation of ASEAN Economic Community (AEC) in 2015 has spread out both chances and challenges for nation members on the road to achieve a highly integrated and cohesive economy. To support for economic development, the banking systems in many ASEAN countries are still a primary source for raising capital. Banking assets made up about $82 \%$ of total financial assets in ASEAN (ADB, 2013).

Employing 2658 observation from 276 unique banks in 6 ASEAN countries, we find a U-shaped effect of credit risk on both risk-free and risk-adjusted TE with a negative coefficient of NPL ratio and a positive coefficient of NPL ratio squared. This finding is different from previous studies when they focus on the linear effect of risk on efficiency. Our finding raises a concern on a possible incentive for banks following greater risk preferences to improve their efficiency. We also find a significant difference in risk-adjusted TE and risk-free one under radial and nonradial estimation, using both constant returns to scale (CRS) and variable returns to scale (VRS) technologies. As far as we know, this paper is among the pioneer papers in incorporating risk into efficiency measurement in ASEAN countries.

The remainder of this paper is organized as follows. In Section 2, the literature on incorporating risk in banking efficiency analysis in the ASEAN region is reviewed. In Section 3, we describe the methodology used in the paper and Section 4 discusses the data and input/output selection. Section 5 presents the technical efficiency results. Section 6 discusses the effect of credit risk on efficiency and, finally, the conclusion and future research are given in section 7.

\section{Literature on Incorporating Risk in Banking Efficiency in ASEAN}

\subsection{The Effect of Risk on Efficiency}

There are two strands of focusing on incorporating risks into efficiency. One regards risk as exogenous to analyze efficiency effects and the other incorporates endogenous risk into the production analysis (Chang and Chiu 2006). Berger and DeYoung (1997) consider risk as an exogenous in a Granger-causality model to examine the relationship between risk and cost efficiency. By a totally different way, Chang (1999) following the nonparametric model proposed by Fare, Grosskopf, and Lovell (1985) treats risks as endogenous and undesirable outputs namely NPLs, loan loss provisions, and risky assets. To test the statistically significant differences between efficiency scores when employing three risk indicators alternatively, he uses ANOVA, Kruskal-Wallis and Wilcoxon rank-sum methods. Zhu, Wang et al. (2016) call on the advantages of both parametric and non-parametric directional distance function to estimate efficiency of commercial banks in China during 2004-2011 and use NPLs as a proxy for risk as one undesirable outputs. Collecting unbalanced panel data over the period 1995-2008 from 17 Central and Eastern European countries, Huang, Chiang et al. (2015) develop a new meta-frontier directional technology distance function under an SFA framework and regard NPLs as an undesirable output in cost efficiency estimation.

Whereas most previous studies focus on using credit risk to explain variation in bank efficiency, Chang and Chiu (2006) employ both market risk (Value at risk or VaR) and credit risk (NPL). They measure efficiency using a data envelopment analysis (DEA) model four different scenarios: without risk, with credit risk or market risk only, with both risk types and then the Wilcoxon matched-pairs signed-ranks test is used to test statistically significant differences in efficiency index of each scenario. Then they investigate the effect of the risks on efficiency via Tobit regressions. However, no significant effect of the two types of risk on efficiency is found for commercial banks in Taiwan during 1996-2000. Sarmientoa and Galán (2015) propose a stochastic frontier analysis (SFA) model relying on a Bayesian method to capture the influence of risk-taking (credit risk, liquidity, capital, and market risk) on cost and profit efficiency of different types of Colombian banks for the period 2002-2012.

\subsection{The Effect of Risk on Efficiency in the ASEAN Banking Sector}

The matter of incorporating risks into the banking efficiency estimation in ASEAN banks is related in some ways. Karim, Sok-Gee et al. (2010) apply the SFA approach to examine the relationship between efficiency and NPLs of banks in Malaysia and Singapore between 1995 and 2000. They use the normal-gamma efficiency distribution model proposed by Greene (1990) to estimate cost efficiency scores and then regress them against NPLs and other control variables. The relationship between NPLs and efficiency is believed as two-way directional one hence a Tobit simultaneous equation regression model is used for the simultaneity effect. Manlagnit (2011) finds domestic banks are less efficient than foreign ones and risk reduces efficiency in Philippine from 1990 to 2006.

The DEA approach is employed by many more researchers by its flexibility in not requiring the pre-specification of the production function, its linearity and its suitability for relatively small data size for each banking system as explanations from Gardener, Molyneux et al. (2011). Khan (2014) proposes the intermediation DEA approach with an input-oriented model to examine the effects of external variables on efficiency of commercial banks in five 
Southeast Asian countries during 1999-2005.

Laeven (1999) also applies the DEA technique to capture the inefficiencies of commercial banks in five Southeast Asian countries (Indonesia, Korea, Malaysia, Philippines, and Thailand) for the pre-crisis period 1992-1996 with some adjustments. Choosing the intermediate approach, Laeven (1999) based on the output orientation to calculate technical efficiency and pointed out that, due to weak enforcement of banking regulation, bad loan data may not be inadequately reported as NPLs so applying this data in efficiency models might lead to incorrect conclusions. In the case of East Asia, until 1997, loans were viewed as NPL when these loans are overdue by at least one year. Due to this reason, banks have better shape than they are. Therefore, Laeven (1999) chooses excessive loan growth as a good proxy for bank risk-taking, instead of NPLs. Yueh-Cheng Wu (2016) applies newly developed dynamic network DEA (DN-DEA) formulated by Tone and Tsutsui (2014) to estimate efficiency

\section{Methodology}

We use data envelopment models to estimate radial and nonradial TE scores. To account for credit risk, we construct a proxy which is equal to one minus the ratio of nonperforming loans to gross loans to be an output. We construct the proxy because the radial and nonradial approaches are assumed to maximized outputs presented by a constraint $\sum_{k=1}^{K} z_{k} y_{k m} \geq y_{k m}, m=1, \ldots, M$ in input-orientation (as shown in Equation 3 and 4 ). In that sense, maximizing the proxy means minimizing the bad output.

The radial TE, also name as Debreu-Farrell measure of efficiency (Debreu, 1951; Farrell, 1957). For each point $k(k=1, \ldots, K)$ vector $x_{k}=\left(x_{k 1}, \ldots, x_{k N}\right) \in \mathfrak{R}^{N}$ denotes $N$ inputs, vector $y_{k}=\left(y_{k 1}, \ldots, y_{k M}\right) \in \mathfrak{R}^{M}$ denotes $M$ outputs. Outputs are producible from inputs under a technology T:

$$
T=\{(x, y): x \text { can be used by banks to produce }(y)\}
$$

The production set is characterised by:

$$
P(x) \equiv\{y:(x, y) \in T\}
$$

To compute the radial input-based TE, we solve linear programming constraints for each data point $k(k=1, \ldots, K)$ :

$$
\begin{aligned}
& \hat{F}_{k}^{o}\left(y_{k}, x_{k}, y, x \mid C R S\right)=\min _{\lambda, z} \lambda \\
& \text { s.t. } \sum_{k=1}^{K} z_{k} y_{k m} \geq y_{k m}, m=1, \ldots, M \\
& \sum_{k=1}^{K} z_{k} x_{k n} \leq x_{k n} \lambda, n=1, \ldots, N \\
& z_{k} \geq 0,
\end{aligned}
$$

where $y$ is $K \times M$ matrix of outputs, $x$ is $K \times N$ matrix of inputs. The estimate of $P(x)$ is the smallest convex free-disposal hull that envelops the observed data, and upper boundary of which is a piece-wise linear estimate of the true best-practice frontier of $P(x)$. Equation (2) is for constant returns to scale $(C R S)$ specification. Other returns to scale $(V R S)$ a convexity constraint $\sum_{k=1}^{K} z_{k}=1$ is added.

The radial method proportionally shrinks $N$ inputs $x_{k}=\left(x_{k 1}, \ldots, x_{k N}\right)$ until it finds a frontier. At the frontier point, some outputs can be increased further (slack of outputs). The nonradial measure of TE or Russell measure can accommodate such slacks. The Russell measure can solve this problem by:

$$
\begin{aligned}
& \widehat{R M}_{k}^{o}\left(y_{k}, x_{k}, y, x \mid C R S\right)=N^{-1} \min _{\lambda, z} \sum_{n=1}^{N} \lambda_{n} \\
& \text { s.t. } \sum_{k=1}^{K} z_{k} y_{k m} \geq y_{k m}, m=1, \ldots, M
\end{aligned}
$$




$$
\begin{aligned}
& \sum_{k=1}^{K} z_{k} x_{k n} \leq x_{k n} \lambda_{n}, n=1, \ldots, N \\
& z_{k} \geq 0 .
\end{aligned}
$$

where $\widehat{R M}_{k}^{i}$ is the nonradial input-based Russel TE. The nonradial measure collapses to radial when $\lambda_{n}=$ $\lambda, \forall m$, and $x_{k n}>0$.

\section{Data Statistics}

We collect the financial statement from FitchConnect. Relying on the the database, we compile unbalanced panel data from 2000-2015 from 6 ASEAN countries, including Cambodia, Indonesia, Malaysia, Philippines, Thailand, and Vietnam; exclude commercial banks in Singapore because most of the commercial banks in Singapore are subsidiaries of international banks. We exclude bank-year observations with missing values for our input and output variables, forming a sample of 276 unique banks with 2,658 bank-year observations.

Table 1. Descriptive statistics for the sample (USD million)

\begin{tabular}{lcrr}
\hline Variables & Symbol & Mean & Std. Dev. \\
\hline Outputs & & & \\
Net loans & $y_{1}$ & 3742.05 & 6778.46 \\
Other earning assets & $y_{2}$ & 1784.07 & 3013.66 \\
$\quad$ Noninterest income & $y_{3}$ & 74.93 & 136.94 \\
$\quad$ Proxy for credit risk (\%) & $b$ & 97.05 & 4.69 \\
Inputs & & & \\
Labour & $x_{1}$ & 62.56 & 107.38 \\
Physical capital & $x_{2}$ & 69.03 & 128.24 \\
Borrowed funds & $x_{3}$ & 5221.27 & 8976.97 \\
Environment & & & \\
Equity/Total assets & $z_{1}$ & 0.14 & 0.11 \\
Bank size (logarithm value of total assets) & $z_{2}$ & 7.46 & 1.81 \\
Diversification (Net loans/Total assets) & $z_{3}$ & 0.54 & 0.18 \\
Off-balance sheet items/Total assets & $z_{4}$ & 0.17 & 0.21 \\
GDP growth (\%) & $z_{5}$ & 5.31 & 1.96 \\
\hline
\end{tabular}

This table describe data statistics of our variables used in this paper. To account for credit risk, we construct a proxy for credit risk which is equal to one minus the ratio of nonperforming loans to gross loans to be an output.

Source: authors' computation from FitchConnect.

We identify inputs and outputs in accordance with the intermediation approach. For the inputs, we select labor expense $\left(x_{1}\right)$, fixed assets proxied for physical capital $\left(x_{2}\right)$ and borrowed funds $\left(x_{3}\right)$ which are total deposits and short-term borrowings. For the desirable outputs, we employ total loans $\left(y_{1}\right)$, investment $\left(y_{2}\right)$, and noninterest income $\left(y_{3}\right)$. In addition to these good outputs, we consider the ratio of non-performing loans to gross loans $(b)$ as a proxy for undesirable output.

To test for the effect of risk preference on efficiency, we include micro and macro environmental factors to reflect the different environments to explain technical efficiency. The micro factors include the ratio of equity to total assets $\left(z_{1}\right)$, bank size $\left(z_{2}\right)$ as the logarithm value of total assets, diversification $\left(z_{3}\right)$ as the ratio of net loans to total assets, the ratio of off-balance sheet items to total assets $\left(z_{4}\right)$. We use GDP growth to represent the overall economic condition.

Table 1 shows the sample statistics for inputs, outputs, and environmental factors. The average amounts of good outputs, including loans, investments, noninterest income, are 3,742, 1784, and 75 million US dollars, respectively. The proxy for credit risk is $97 \%$, suggesting that the nonperforming loan ratio is about $3 \%$. Three inputs, labor expense, fixed assets, and borrowed funds, have means at 73, 81, and 6,283 million US dollars, respectively. The 
bank characteristics reveal banks in ASEAN 6 with equity, bank size, diversification, the ratio of off-balance sheet items to total assets are $0.14,7.46,0.54,0.17$, respectively. Finally, the macro environment factor, the average GDP growth rate, is $5.31 \%$.

\section{Technical Efficiency Estimation}

In this section, we show kernel density distribution of efficiency. As nonperforming loans (credit risk) is incorporated in TE scores, we call these scores are risk-adjusted TE. We measure the TE scores under both constant returns to scale (CRS) and variable returns to scale (VRS) specifications of the production technology. The annual arithmetic average values for risk-adjusted and risk-free TE are depicted in Figures 1 to 4 . In general, the four figures show risk-adjusted TE (the dash lines) tends to skew to the right of risk-free TE (the blue solid lines), suggesting a bias if the risk is ignored.

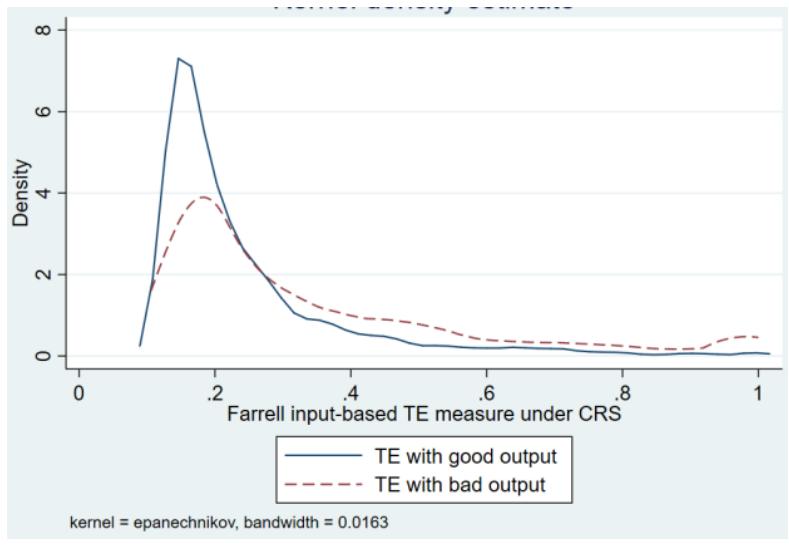

Figure 1. Kernel density distribution of radial TE (CRS)

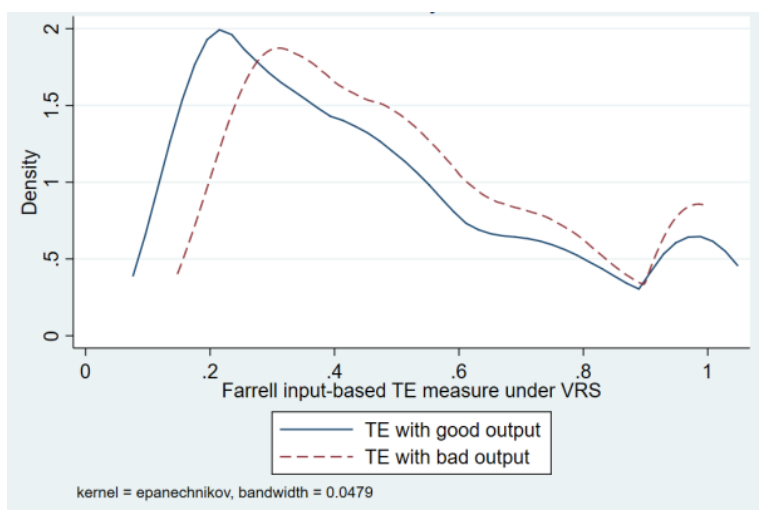

Figure 3. Kernel density distribution of radial TE (VRS)

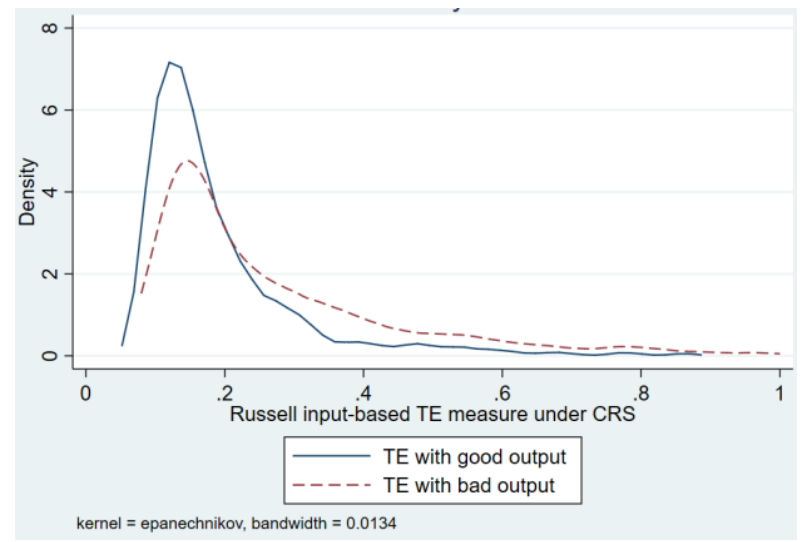

Figure 2. Kernel density distribution of nonradial TE (CRS)

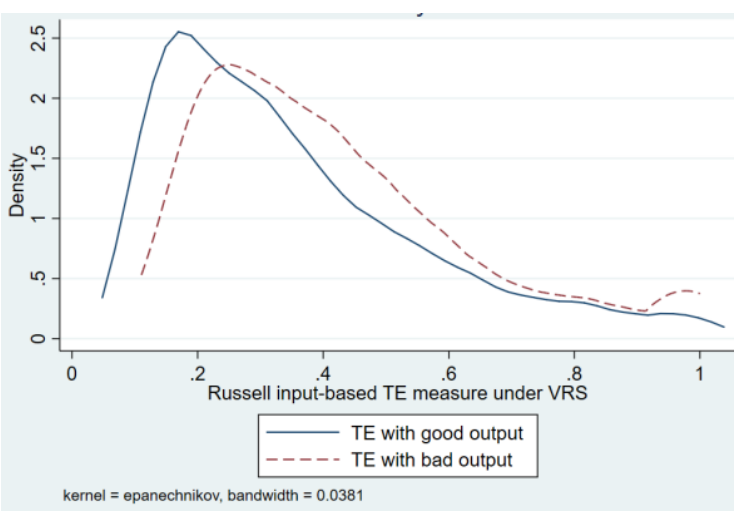

Figure 4. Kernel density distribution of nonradial TE (VRS)

Source: authors' computation from FitchConnect

Table 2 shows the risk-free and risk-adjusted TE scores under both CRS and VRS over period 2000-2015. The TE scores display a downtrend during the period. One interesting finding is that risk-adjusted TE scores tend to have a clear and strong reduction than risk-free TE ones. For example, risk-adjusted radial TE under CRS (in Column 2) collapses from 0.43 in 2000 to 0.34 in 2015. Similarly, risk-adjusted nonradial TE under VRS (in Column 8) falls from 0.46 in 2000 to 0.40 in 2015. By contrast, risk-free radial TE under CRS (in Column 1) slightly drops from 0.26 in 2000 to 0.24 in 2015. Or risk-free radial TE under VRS (in Column 5) marginally decreases from 0.47 in 2000 to 0.46 in 2015. The difference in the tendency magnitude of risk-adjusted TE and risk-free TE is another evidence of a 
possible bias when risk is disregarded.

Table 2. Risk-free and risk-adjusted TE scores

\begin{tabular}{|c|c|c|c|c|c|c|c|c|}
\hline & \multicolumn{4}{|c|}{ CRS } & \multicolumn{4}{|c|}{ VRS } \\
\hline & \multicolumn{2}{|c|}{ Radial } & \multicolumn{2}{|c|}{ Nonradial } & \multicolumn{2}{|c|}{ Radial } & \multicolumn{2}{|c|}{ Nonradial } \\
\hline & (1) & (2) & (3) & (4) & (5) & (6) & (7) & (8) \\
\hline & Risk-free & Risk-adjusted & Risk-free & Risk-adjusted & Risk-free & Risk-adjusted & Risk-free & Risk-adjusted \\
\hline 2000 & 0.26 & 0.43 & 0.21 & 0.33 & 0.47 & 0.59 & 0.39 & 0.46 \\
\hline 2001 & 0.24 & 0.41 & 0.19 & 0.31 & 0.49 & 0.56 & 0.37 & 0.43 \\
\hline 2002 & 0.24 & 0.39 & 0.19 & 0.31 & 0.49 & 0.55 & 0.37 & 0.43 \\
\hline 2003 & 0.23 & 0.38 & 0.18 & 0.29 & 0.47 & 0.53 & 0.35 & 0.41 \\
\hline 2004 & 0.23 & 0.37 & 0.18 & 0.29 & 0.46 & 0.53 & 0.35 & 0.42 \\
\hline 2005 & 0.24 & 0.38 & 0.19 & 0.30 & 0.47 & 0.53 & 0.36 & 0.43 \\
\hline 2006 & 0.24 & 0.35 & 0.19 & 0.28 & 0.46 & 0.52 & 0.35 & 0.41 \\
\hline 2007 & 0.25 & 0.33 & 0.20 & 0.27 & 0.43 & 0.52 & 0.34 & 0.42 \\
\hline 2008 & 0.24 & 0.32 & 0.19 & 0.26 & 0.43 & 0.50 & 0.34 & 0.41 \\
\hline 2009 & 0.22 & 0.31 & 0.18 & 0.25 & 0.42 & 0.49 & 0.32 & 0.39 \\
\hline 2010 & 0.24 & 0.32 & 0.19 & 0.25 & 0.44 & 0.53 & 0.35 & 0.42 \\
\hline 2011 & 0.24 & 0.33 & 0.19 & 0.26 & 0.45 & 0.53 & 0.35 & 0.43 \\
\hline 2012 & 0.25 & 0.33 & 0.19 & 0.26 & 0.46 & 0.53 & 0.36 & 0.43 \\
\hline 2013 & 0.25 & 0.32 & 0.19 & 0.25 & 0.45 & 0.53 & 0.36 & 0.43 \\
\hline 2014 & 0.25 & 0.32 & 0.19 & 0.25 & 0.46 & 0.52 & 0.36 & 0.43 \\
\hline 2015 & 0.24 & 0.33 & 0.18 & 0.24 & 0.46 & 0.52 & 0.33 & 0.40 \\
\hline erage & 0.24 & 0.34 & 0.19 & 0.27 & 0.46 & 0.53 & 0.35 & 0.42 \\
\hline
\end{tabular}

Source: authors' computation from FitchConnect

\section{Effect of Credit Risk on Efficiency}

The previous section has demonstrated substantial variability between the risk-free TE and risk-adjusted TE of commercial banks in six ASEAN countries across radial and nonradial measures and under CRS and VRS technology. In this section, we investigate the effect of credit risk on risk-free and risk-adjusted TE relying on OLS and truncated regression. As the TE score ranges from 0 to 1 , so the first technique employed in this paper is truncated regression which addresses the bias introduced when using OLS regression with truncated data. However, we also employ the OLS estimation because it has some interesting features, including bank and year fixed effects and robust standard errors. To check robustness, we resample data into two bank groups by size median and employ truncated regressions and OLS estimation. The overall conclusion is that credit risk has a U-shaped effect on bank efficiency across different regression methods, small and big banks, CSR and VRS technology, and radial and nonradial measures of efficiency.

\subsection{Baseline Analysis}

We use both the truncate regression and OLS to examine the effect of risk on risk-free and risk-adjusted TE in the baseline analysis. Table 3 represents the results when risk-free TE is the dependent variable. We find a U-shaped relationship between credit risk and risk-free efficiency with a negative coefficient of NPL ratio and a positive coefficient of NPL ratio squared. A negative coefficient of NPL ratio implies that banks with higher NPL ratio can have lower efficiency because the banks are required to use their resources for loan loss provisions (and thus produce lower net loans). The negative effect is in line with the one in (Gaganis and Pasiouras, 2013; Luo et al., 2016). In the same vein, Mamatzakis (2015) suggests that the negative effect becomes stronger for banks with higher efficiency scores. Or Sun and Chang (2011) find that Loan loss reserve and ROA volatility have negative effects on efficiency for banks with high levels of these risk factors.

We further investigate a non-linear effect of credit risk on efficiency, which is mostly ignored in the literature. We 
find that a U-shaped effect exists when the coefficient of NPL squared is positive and the coefficient of NPL is negative (and both are significant). The negative coefficient of NPL ratio seems to suggest that banks have no incentive for risk-taking because a higher ratio of NPL is related to a lower level of efficiency. However, the positive coefficient of NPL squared and the negative coefficient of NPL indicate a change in the direction (from negative to positive) of the effect of credit risk on efficiency, and the effect becomes positively stronger when NPL ratio increases significantly. We argue that the positive effect of NPL squared can occur when banks could perform more efficiently when they accept an aggressively risk preference.

Table 3. Effect of credit risk on risk-free TE

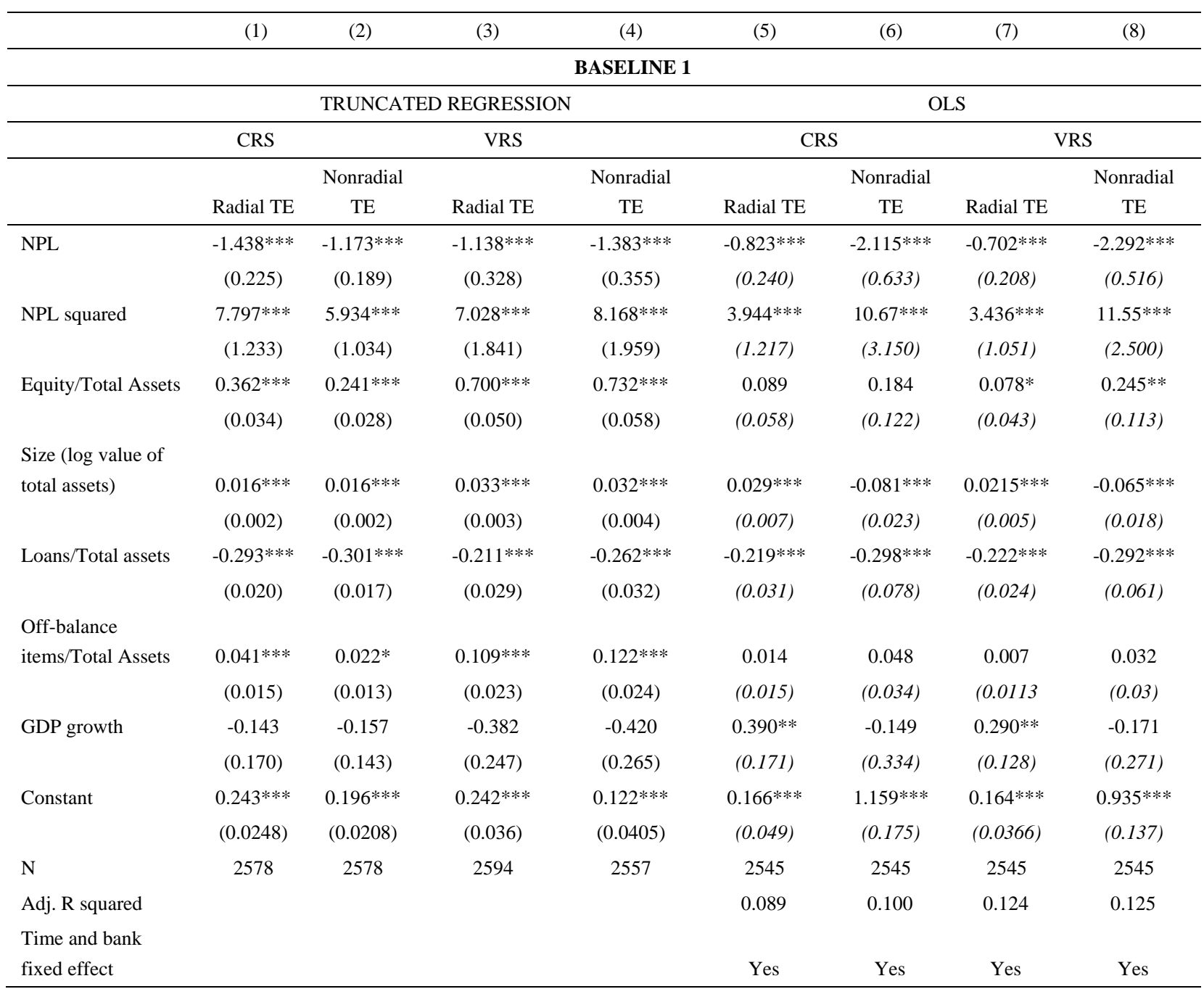

This table presents the impacts of NPL on risk-free TE. Results of the truncated regressions and panel data regressions are shown in Columns 1 to 4 and Columns 5 to 8, respectively.

$* * *, * *$ and $*$ indicate statistical significance at the $1 \%, 5 \%$ and $10 \%$ levels. 
Table 4. Effect of credit risk on risk-adjusted TE

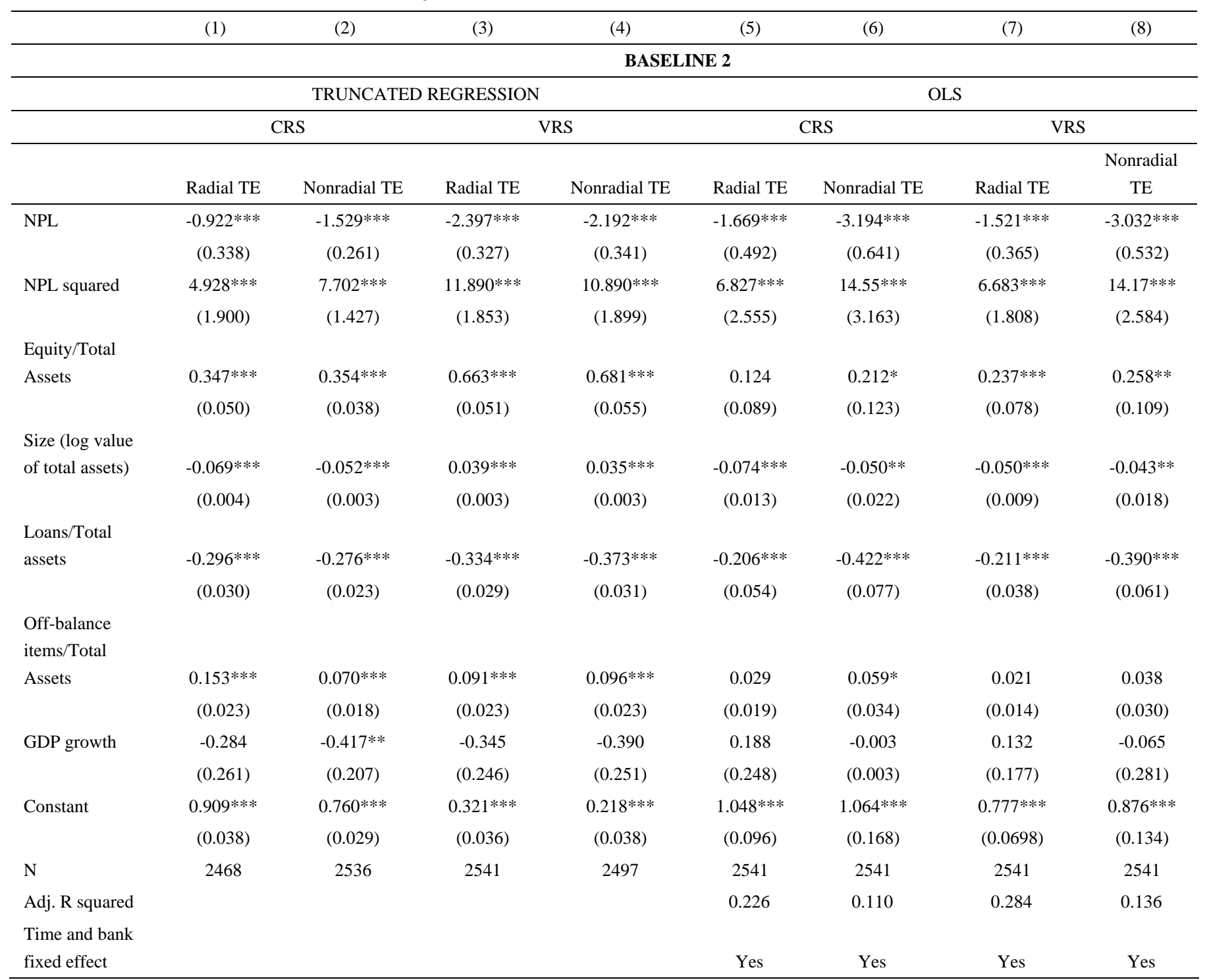

This table presents the impacts of NPL on risk-adjusted TE. Results of the truncated regressions and panel data regressions are shown in Columns 1 to 4 and Columns 5 to 8, respectively. $* * *, * *$ and $*$ indicate statistical significance at the $1 \%, 5 \%$ and $10 \%$ levels.

Among control variables, only diversification (captured by the ratio of net loans to total assets) maintains its significant and consistent coefficient with negative sign. This means that banks focusing more on lending activities have less efficiency. This finding is supported by Luo et al. (2016) who find that more diversified bank business enjoys greater profit efficiency. However, our finding on efficiency is in opposite to the finding of Fiordelisi et al. (2011) who argue that more specialized banks benefits more from scale, enabling them to be more advantageous in cost reduction than their diversified competitors. Moreover, banks with more finding diversification can signal the market that they may not have enough stable funding sources (customer deposits, equity and long-term debts) so that they have to mobilize funds from short-term debts or interbank markets. These types of funding cannot provide a stable strategy to provide long-term products which have higher yields than short-term ones.

The macro economic indicator, GDP growth, has no significant effect on efficiency. This finding is surprised because we expect a positive effect. Our finding on the effect of GDP growth is in line with Luo et al. (2016) who also find no evidence on the effect of GDP growth on bank efficiency.

Table 4 displays the results when risk-adjusted TE is the dependent variable. While the coefficient of NPL is 
negative, that of NPL squared is positive and significant. This means that a U-shaped effect of NPL on the risk-adjusted TE exists. Coefficient of diversification is significant while those of other control variables are not. These results are similar to those in Table 3.

\subsection{Robustness Checks}

To check robustness of the U-shaped effect of NPL ratio on efficiency, we resample our data sample into two groups: small and big banks (relying on size median) using the same truncated regressions and OLS estimation with bank-year fixed effect. We split the data sample because we argue that bank size may have different risk preferences.

Table 5. The effect of credit risk on risk-free TE over two bank groups using truncated regressions

\begin{tabular}{|c|c|c|c|c|c|c|c|c|}
\hline & (1) & (2) & (3) & (4) & (5) & (6) & (7) & (8) \\
\hline & \multicolumn{8}{|c|}{ TRANCATED REGRESSIONS } \\
\hline & \multicolumn{4}{|c|}{ RADIAL } & \multicolumn{4}{|c|}{ NONRADIAL } \\
\hline & \multicolumn{2}{|c|}{ CRS } & \multicolumn{2}{|c|}{ VRS } & \multicolumn{2}{|c|}{ CRS } & \multicolumn{2}{|c|}{ VRS } \\
\hline & Small & Big & Small & Big & Small & Big & Small & Big \\
\hline \multirow[t]{2}{*}{ NPL } & -0.326 & $-1.864 * * *$ & $-0.865^{* *}$ & $-1.544 * * *$ & -0.229 & $-1.417 * * *$ & $-0.696^{* *}$ & $-1.997 * * *$ \\
\hline & $(0.225)$ & $(0.265)$ & $(0.413)$ & $(0.417)$ & $(0.176)$ & $(0.210)$ & $(0.293)$ & $(0.360)$ \\
\hline \multirow[t]{2}{*}{ NPL squared } & $4.276^{* * *}$ & $7.463 * * *$ & $8.322 * * *$ & $6.939 * * *$ & $3.004 * * *$ & $5.479 * * *$ & $6.216 * * *$ & $9.174 * * *$ \\
\hline & $(1.213)$ & $(1.578)$ & $(2.222)$ & $(2.483)$ & $(0.949)$ & $(1.252)$ & $(1.575)$ & $(2.146)$ \\
\hline \multirow[t]{2}{*}{ Equity/Total Assets } & $0.235 * * *$ & $0.387 * * *$ & $0.263 * * *$ & $0.851 * * *$ & $0.203 * * *$ & $0.294 * * *$ & $0.280 * * *$ & $0.633 * * *$ \\
\hline & $(0.030)$ & $(0.056)$ & $(0.055)$ & $(0.089)$ & $(0.023)$ & $(0.045)$ & $(0.0389)$ & $(0.0765)$ \\
\hline \multicolumn{9}{|l|}{ Size (log value of total } \\
\hline \multirow[t]{2}{*}{ assets) } & $0.039 * * *$ & $-0.017 * * *$ & $-0.082 * * *$ & $0.157 * * *$ & $0.029 * * *$ & $-0.010^{* * *}$ & $-0.067 * * *$ & $0.130 * * *$ \\
\hline & $(0.003)$ & $(0.004)$ & $(0.006)$ & $(0.006)$ & $(0.003)$ & $(0.003)$ & $(0.005)$ & $(0.005)$ \\
\hline \multirow[t]{2}{*}{ Loans/Total assets } & $-0.198 * * *$ & $-0.216^{* * * *}$ & $-0.290 * * *$ & $-0.321 * * *$ & $-0.213 * * *$ & $-0.204 * * *$ & $-0.263 * * *$ & $-0.297 * * *$ \\
\hline & $(0.020)$ & $(0.024)$ & $(0.036)$ & $(0.038)$ & $(0.016)$ & $(0.019)$ & $(0.026)$ & $(0.032)$ \\
\hline \multicolumn{9}{|l|}{ Off-balance } \\
\hline \multirow[t]{2}{*}{ items/Total Assets } & $0.074 * * *$ & 0.019 & $0.153 * * *$ & 0.012 & $0.046 * * *$ & 0.007 & $0.092 * * *$ & 0.024 \\
\hline & $(0.019)$ & $(0.015)$ & $(0.034)$ & $(0.024)$ & $(0.015)$ & $(0.012)$ & $(0.024)$ & $(0.021)$ \\
\hline \multirow[t]{2}{*}{ GDP growth } & 0.270 & -0.162 & -0.368 & $-0.519 * *$ & 0.091 & -0.171 & -0.194 & $-0.456 * *$ \\
\hline & $(0.205)$ & $(0.165)$ & $(0.375)$ & $(0.260)$ & $(0.160)$ & $(0.131)$ & $(0.266)$ & $(0.225)$ \\
\hline \multirow[t]{2}{*}{ Constant } & 0.041 & $0.531 * * *$ & $1.032 * * *$ & $-0.775^{* * *}$ & $0.068 * * *$ & $0.414 * * *$ & $0.832 * * *$ & $-0.635 * * *$ \\
\hline & $(0.030)$ & $(0.036)$ & $(0.055)$ & $(0.057)$ & $(0.024)$ & $(0.028)$ & $(0.039)$ & $(0.049)$ \\
\hline \multirow[t]{2}{*}{$\mathrm{N}$} & 1200 & 1345 & 1200 & 1345 & 1200 & 1345 & 1200 & 1345 \\
\hline & 369.04 & 267.71 & 481.26 & 782.38 & 483.02 & 281.43 & & 736.32 \\
\hline Wald chi2 (p-val.) & $(0.000)$ & $(0.000)$ & $(0.000)$ & $(0.000)$ & $(0.000)$ & $(0.000)$ & $709.42(0.000)$ & $(0.000)$ \\
\hline
\end{tabular}

This table presents the impacts of NPL on risk-free TE for small and big banks using truncated regressions. Columns 1 to 4 present the truncated regressions with radial TE. Columns 5 to 8 present the truncated regressions with nonradial TE. $* * * * *$ and $*$ indicate statistical significance at the $1 \%, 5 \%$ and $10 \%$ levels. 
Table 6. The effect of credit risk on risk-free TE over two bank groups using OLS estimation.

\begin{tabular}{|c|c|c|c|c|c|c|c|c|}
\hline & (1) & (2) & (3) & (4) & (5) & (6) & (7) & (8) \\
\hline & \multicolumn{8}{|c|}{ OLS } \\
\hline & \multicolumn{4}{|c|}{ RADIAL } & \multicolumn{4}{|c|}{ NONRADIAL } \\
\hline & \multicolumn{2}{|c|}{ CRS } & \multicolumn{2}{|c|}{ VRS } & \multicolumn{2}{|c|}{ CRS } & \multicolumn{2}{|c|}{ VRS } \\
\hline & Small & Big & Small & Big & Small & Big & Small & Big \\
\hline \multirow[t]{2}{*}{ NPL } & $-0.503^{*}$ & $-1.180^{* * *}$ & -0.936 & $-2.218 * * *$ & -0.381 & $-0.998 * * *$ & $-0.953 * *$ & $-2.680 * * *$ \\
\hline & $(0.266)$ & $(0.408)$ & $(0.655)$ & $(0.693)$ & $(0.235)$ & $(0.324)$ & $(0.437)$ & $(0.731)$ \\
\hline \multirow[t]{2}{*}{ NPL squared } & $3.568 * *$ & $4.795 * * *$ & $5.920 *$ & $10.95 * * *$ & $2.791 * *$ & $4.212 * * *$ & $5.622 * *$ & $13.74 * * *$ \\
\hline & (1.613) & (1.814) & (3.103) & $(3.554)$ & $(1.382)$ & $(1.443)$ & $(2.201)$ & $(3.819)$ \\
\hline \multirow[t]{2}{*}{ Equity/Total Assets } & 0.049 & $0.188^{*}$ & -0.0611 & $0.641 * * *$ & 0.055 & 0.124 & $0.168^{*}$ & 0.274 \\
\hline & $(0.059)$ & $(0.110)$ & $(0.114)$ & $(0.237)$ & $(0.045)$ & $(0.080)$ & $(0.094)$ & $(0.296)$ \\
\hline \multirow[t]{2}{*}{ Size (log value of total assets) } & $0.028 * * *$ & 0.020 & $-0.110^{* * *}$ & $0.083^{* *}$ & $0.025^{* * *}$ & 0.016 & $-0.066^{* * *}$ & 0.049 \\
\hline & $(0.010)$ & $(0.020)$ & $(0.019)$ & $(0.033)$ & $(0.008)$ & $(0.016)$ & $(0.014)$ & $(0.031)$ \\
\hline \multirow[t]{2}{*}{ Loans/Total assets } & $-0.179 * * *$ & $-0.301 * * *$ & $-0.141 *$ & $-0.486^{* * *}$ & $-0.204 * * *$ & $-0.280 * * *$ & $-0.161 * * *$ & $-0.461 * * *$ \\
\hline & $(0.043)$ & $(0.052)$ & $(0.077)$ & $(0.095)$ & $(0.031)$ & $(0.042)$ & $(0.051)$ & $(0.088)$ \\
\hline \multirow[t]{2}{*}{ Off-balance items/Total Assets } & 0.036 & 0.001 & 0.037 & 0.026 & 0.019 & -0.001 & 0.041 & 0.010 \\
\hline & $(0.031)$ & $(0.016)$ & $(0.044)$ & $(0.030)$ & $(0.022)$ & $(0.013)$ & $(0.034)$ & $(0.031)$ \\
\hline \multirow[t]{2}{*}{ GDP growth } & $0.475^{* *}$ & $0.465^{* *}$ & $0.706^{*}$ & 0.131 & 0.307 & $0.349^{* *}$ & 0.412 & 0.073 \\
\hline & $(0.232)$ & $(0.218)$ & $(0.412)$ & $(0.376)$ & $(0.206)$ & $(0.155)$ & $(0.309)$ & $(0.325)$ \\
\hline \multirow[t]{2}{*}{ Constant } & $0.154 * *$ & 0.263 & $1.234 * * *$ & -0.089 & $0.140 * * *$ & $0.227 *$ & $0.860 * * *$ & 0.119 \\
\hline & $(0.060)$ & $(0.162)$ & $(0.121)$ & $(0.279)$ & $(0.047)$ & $(0.135)$ & $(0.082)$ & $(0.266)$ \\
\hline $\mathrm{N}$ & 1200 & 1345 & 1200 & 1345 & 1200 & 1345 & 1200 & 1345 \\
\hline Adj. R squared & 0.074 & 0.117 & 0.347 & 0.343 & 0.118 & 0.155 & 0.423 & 0.334 \\
\hline
\end{tabular}

This table presents the impacts of NPL on TE for small and big banks using OLS estimation. Columns 1 to 4 present the truncated regressions with radial TE. Columns 5 to 8 present the truncated regressions with nonradial TE. ***, ** and $*$ indicate statistical significance at the $1 \%, 5 \%$ and $10 \%$ levels.

We replicate the truncated regression and OLS as in the baseline for two bank groups. Table 5 shows the results when dependent variable is the risk-free TE using truncated regressions. Under truncated regression when risk-free TE is the dependent variable, the NPL squared still maintains significant and positive coefficient regardless banks are small or big. For small banks, some coefficients of NPL are insignificant (as in Column 1 and 5). However, all coefficients of NPL are significant for big banks. This insignificance of NPL for small banks suggests that the effect of credit risk on risk-free TE differs from the one of big banks in the sense that the effect (greater risk, greater efficiency) is stronger for small banks. This implies small banks have more incentives to take risk than big banks. Among control variables, coefficients of diversification and the equity ratio are significant. While diversification obtains a significant and negative coefficient, the equity ratio has a positive one. The positive coefficient of the equity ratio indicates that better capitalized banks can achieve greater efficiency. We assume that banks depend on its equity level to have better access to borrowing sources and thus can provide more loans or investment at lower funding costs.

Table 6 shows the results when dependent variable is the risk-free TE using OLS estimation. The coefficient of the NPL is insignificant for small banks in Columns 3 and 5, indicating that small banks have a stronger effect of credit risk on efficiency than big banks. However, the NPL squared maintains its all significant and positive coefficients regardless of small or big banks. Among control variables, only diversification has consistently negative coefficients over two bank groups.

In addition to the robustness checks as shown in Table 5 and 6, we also use the risk-adjusted TE as the dependent variable using truncated regression and OLS estimation over two bank groups. The coefficient of NPL squared is still significant and positive. We can provide these results upon requests. This result implies that a U-shaped effect of credit risk is robust across multiple measures of efficiency and bank groups. 
In this section, we have investigated the effect of credit risk on efficiency. We find a U-shaped effect of credit risk on the efficiency. As far as we know, this finding is different from previous studies in the sense that previous ones focus on linear relationship. Because of the U-shaped effect, banks may have an incentive to follow aggressive risk preferences in order to improve their efficiency.

\section{Conclusion}

We incorporate credit risk into technology efficiency using redial and nonradial measures of technical efficiency under both CRS and VRS technology. By using the ratio of net loans to gross loans (good output) to replace NPL ratio (bad output) in our vector of output, we incorporate credit risk into TE and provide evidence on discrepancies between risk-free TE and risk-adjusted one. Then we investigate the effect of credit risk on both risk-free TE and risk-adjusted TE and contribute to the literature by providing a U-shaped effect of the risk on bank efficiency. This finding shows banks have one incentive to achieve greater efficiency by following aggressively risk preferences.

In this study, we only focus on the effect of credit risk on technical efficiency in ASEAN countries. Further studies may incorporate other types of risk such as systemic risk or liquidity risk into bank efficiency or examine the U-shaped relationship between risks and bank efficiency in other countries.

\section{References}

ADB, A. (2013). The road to ASEAN financial integration: A combined study on assessing the financial landscape and formulating milestones for monetary and financial integration in ASEAN. Manila: Asian Development Bank.

Basel Committee on Banking Supervision. (2010). Basel III: International framework for liquidity risk measurement, standards and monitoring.

Basel Committee on Banking Supervision. (2014). Basel III: The net stable funding ratio. Consultative Document.

Berger, A. N., \& De Young, R. (1997). Problem loans and cost efficiency in commercial banks. Journal of Banking and Finance, 21, 849-870.

Chan, S.-G., Koh, E. H. Y., \& Kim, Y.-C. (2016). Effect of foreign shareholdings and originating countries on banking sector efficiency. Emerging Markets Finance and Trade, 0938(April), 1-25.

Debreu, G. (1951). The coefficient of resource utilization. Econometrica, 19(3), 273-292.

Epure, M., \& Lafuente, E. (2015). Monitoring bank performance in the presence of risk. Journal of Productivity Analysis, 44, 265-281.

Farrell, M. J. (1957). The measurement of productive efficiency. Journal of the Royal Statistical Society. Series A (General), 120(3), 102-139.

Fiordelisi, F., Marques-Ibanez, D., \& Molyneux, P. (2011). Efficiency and risk in European banking. Journal of Banking and Finance, 35.

Fukuyama, H., \& Weber, W. L. (2008). Japanese banking inefficiency and shadow pricing. Mathematical and Computer Modelling.

Gaganis, C., \& Pasiouras, F. (2013). Financial supervision regimes and bank efficiency: International evidence. Journal of Banking and Finance, 37(12), 5463-5475.

Gardener, E., Molyneux, P., \& Nguyen-Linh, H. (2011). Determinants of efficiency in South East Asian banking. The Service Industries Journal, 31(16), 2693-2719.

Huang, T.-H., Chiang, D.-L., \& Tsai, C.-M. (2015). Applying the new metafrontier directional distance function to compare banking efficiencies in Central and Eastern European countries. Economic Modelling, 44, 188-199.

Huang, T. H., \& Chung, M. T. (2017). Do undesirables matter on the examination of banking efficiency using stochastic directional distance functions. Quarterly Review of Economics and Finance, 65, 194-211. https://doi.org/10.1016/j.qref.2016.09.007

Kenjegalieva, K., Simper, R., Weyman-Jones, T., \& Zelenyuk, V. (2009). Comparative analysis of banking production frameworks in eastern european financial markets. European Journal of Operational Research, 198, 326-340.

Luo, Y., Tanna, S., \& De Vita, G. (2016). Financial openness, risk and bank efficiency: Cross-country evidence. 
Journal of Financial Stability, 24, 132-148.

Mamatzakis, E. (2015). Risk and efficiency in the Central and Eastern European banking industry under quantile analysis. Quantitative Finance, 15, 553-567.

Park, K. H., \& Weber, W. L. (2006). A note on efficiency and productivity growth in the Korean Banking Industry, 1992-2002. Journal of Banking and Finance.

Shleifer, A., \& Vishny, R. W. (2010). Unstable banking. Journal of Financial Economics, 97(3), 306-318.

Silva, T. C., Guerra, S. M., Tabak, B. M., \& de Castro Miranda, R. C. (2016). Financial networks, bank efficiency and risk-taking. Journal of Financial Stability, 25, 247-257.

Sun, L., \& Chang, T.-P. (2011). A comprehensive analysis of the effects of risk measures on bank efficiency: Evidence from emerging Asian countries. Journal of Banking \& Finance, 35, 1727-1735.

Wong, W. P., \& Deng, Q. (2016). Efficiency analysis of banks in ASEAN countries. Benchmarking: An International Journal, 23(7), 1798-1817. https://doi.org/10.1108/BIJ-11-2013-0102

Zaini Abd Karim, M., Chan, S.-G., \& Hassan, S. (2010). Bank Efficiency and Non-Performing Loans: Evidence from Malaysia and Singapore. Prague Economic Papers, 19(2), 118-132.

\section{Copyrights}

Copyright for this article is retained by the author(s), with first publication rights granted to the journal.

This is an open-access article distributed under the terms and conditions of the Creative Commons Attribution license (http://creativecommons.org/licenses/by/4.0/). 